\title{
Brachial artery Doppler flux parameters before and after hot flush in Mexican postmenopausal women: preliminary report
}

\author{
Sebastián Carranza-Lira ${ }^{1}$, Karina Vázquez Rodríguez ${ }^{2}$, Sergio Rosales Ortiz ${ }^{3}$ \\ ${ }^{1}$ Research Division in Health, UMAE Hospital of Gineco Obstetricia "Luis Castelazo Ayala”, Social Security Mexican Institute, Mexico DF \\ 2Obstetrics and Gynaecology Resident, UMAE Hospital of Gineco Obstetricia “Luis Castelazo Ayala”, Social Security Mexican Institute, \\ Mexico DF \\ ${ }^{3}$ Ultrasound Service Staff, UMAE Hospital of Gineco Obstetricia “Luis Castelazo Ayala”, Social Security Mexican Institute, Mexico DF
}

\begin{abstract}
Objective: To analyse brachial artery flux parameters in postmenopausal women before and after hot flush.

Material and methods: Two groups of postmenopausal women were studied: Group I, without vasomotor symptoms $(n=10)$ and Group II, with vasomotor symptoms $(n=10)$. In all them a brachial artery Doppler ultrasound was done, measuring before and after hyperaemic stimulus of the arterial diameter (AD), the pulsatility index (PI), and the resistive index (RI). In Group I, measurements were done at baseline and five minutes after. In Group II, measurements were at baseline, and one and five minutes after the hot-flush. Comparison between the groups was done with Mann-Whitney $U$ test, and within the groups with Wilcoxon test.

Results: No differences were found among the groups in Doppler parameters. When comparing each group separately, in Group I, at baseline and at five minutes measurements, the AD was greater after the hyperaemic stimulus than before it. In group II at baseline, the PI was significantly greater after the hyperaemic stimulus than before to it. At the first and fifth minute, the AD was significantly greater after the hyperaemic stimulus than before to it.
\end{abstract}

Conclusions: No differences were found between those who did not have and those who had hot flushes.

Key words: Doppler, hot flushes, arterial diameter, pulsatility index, resistive index, brachial artery, menopause.

\section{Introduction}

Vasomotor symptoms are the most common complaint during the menopausal transition; they are present in up to $80 \%$ of women [1-3], although their frequency changes according to culture and ethnic origin. The frequency increases from $40 \%$ at the beginning of menopausal transition to $60-80 \%$ at the end $[4,5]$. Hot flushes have a negative impact on quality of life and have been related to an increase in cardiovascular risk and bone turnover $[6,7]$.

Hot flushes begin as a sudden heat sensation at the upper part of the chest which quickly generalises, lasting from two to four minutes, and are associated with profuse sweating and occasionally throbs continued, chills, tremors, and anxiety [8]. Vasomotor symptoms have different frequency and intensity between women, and their intensity can be classified as low, moderate, or intense [9] or quantified using an analogue visual scale [10].

Vascular endothelium has a role in vasomotor tone regulation and platelet adhesion. Oxidative stress mod- ifies vasomotor tone modulation due to endothelial nitric oxide inactivation [11].

Endothelial function can be evaluated by brachial artery ultrasound before and after hyperaemic stimulus. This test is a validated, non-invasive test that has been used as a research tool to assess endothelial function [12].

It has been suggested that women with hot flushes have greater risk of cardiovascular events, but to our knowledge endothelial function before and after the hot-flush has never been evaluated, so the objective of this study was to do just that.

\section{Material and methods}

From April to June 2015, 20 postmenopausal women were studied and divided into two groups: Group I, without vasomotor symptoms $(n=10)$ and Group II, with vasomotor symptoms; both groups were without hormone replacement therapy $(n=10)$.

In all of the women age (years), weight $(\mathrm{kg})$, height $(\mathrm{m})$, waist perimeter $(\mathrm{cm})$, and hip perimeter $(\mathrm{cm})$ were 
recorded. Body mass index (BMI, weight/height ${ }^{2}$ ) and the waist/hip ratio (WHR, waist perimeter/hip perimeter) were calculated. Brachial artery Doppler ultrasound was done with a Voluson 730 Pro imaging device (General Electric Healthcare, Austria GM GH) using a $7.5 \mathrm{MHz}$ probe. In both groups the arterial diameter (AD) was measured, and also the pulsatility index (PI) and resistive index (RI) before and after the hyperaemic stimulus were calculated [12].

The AD measurement $(\mathrm{mm})$ was done by placing the transducer perpendicularly to the brachial artery at the distal third of the arm. When the double line image was clearly seen, the distance from one line to another was measured. Later on, the PI was calculated: maximal systolic speed minus minimal diastolic speed divided by the half speed during the complete cycle, and the RI: maximal systolic speed minus final diastolic speed divided by maximal systolic speed.

The hyperaemic stimulus was provoked by placing a sphygmomanometer cuff in the right arm and insufflating it up to $50 \mathrm{mmHg}$ above the maximal systolic blood pressure. Subsequently, the cuff was deflated and withdrawn, and 60 seconds later the AD, PI, and RI were measured again.

In Group I, measurements at baseline and five minutes after were made. In Group II, the measurements were made one minute and five minutes after the hot flush. Two hours after the hot flush, measurements were made again and were considered as the baseline measurement at the time of comparison with Group I.

The magnitude of symptoms was measured with an analogue visual scale $10 \mathrm{~cm}$ in length, in which 0 was the absence of the symptom and 10 its maximum intensity [10].

Sample size was calculated using the Epilnfo 7 program (CDC Atlanta, GA), considering a confidence level of $90 \%$, a power of $90 \%$, and that $70 \%$ of those with

Tab. I. General data of postmenopausal women without and with hot flushes

\begin{tabular}{lccc}
\hline Parameter & $\begin{array}{c}\text { Without hot } \\
\text { flushes }\end{array}$ & $\begin{array}{c}\text { With hot } \\
\text { flushes }\end{array}$ & $p$ \\
\hline Age (years) & $55.5(50-67)$ & $53.5(46-71)$ & NS \\
\hline Weight $(\mathrm{kg})$ & $64.5(42-93)$ & $70.5(60-107)$ & NS \\
\hline Height $(\mathrm{m})$ & $1.54(1.44-1.66)$ & $1.58(1.51-1.66)$ & $<0.035$ \\
\hline $\begin{array}{l}\text { Body mass } \\
\text { index }\end{array}$ & $27.4(17.4-33.7)$ & $28.6(21.7-42.8)$ & NS \\
\hline $\begin{array}{l}\text { Waist perimeter } \\
\text { (cm) }\end{array}$ & $86(78-107)$ & $87.5(76-122)$ & NS \\
\hline $\begin{array}{l}\text { Hip perimeter } \\
\text { (cm) }\end{array}$ & $104(90-119)$ & $102.0(92-132)$ & NS \\
\hline $\begin{array}{l}\text { Waist/Hip ratio } \\
\text { 0.86 (0.75-0.93) }\end{array}$ & $0.88(0.80-0.96)$ & NS \\
\hline Results are in median and interval. & &
\end{tabular}

hot-flushes will have different vascular parameters, so the sample size was nine subjects per group.

Statistical analysis was done with the SPSS program (IBM SPSS Statistics for Windows, Version 20.0. Armonk, NY: IBM Corp). Due to sample distribution, non-parametric statistics were used. The comparison among the groups was carried out with Mann-Whitney $U$ test. In each group separately the comparisons between previous and after hyperaemic stimulus and among the values in the different times were carried out with the Wilcoxon test.

The study was authorised by the Local Committee of Research and Ethics in Research in Health of the Hospital, with registration number R-2015-3606-21. All patients gave their consent to participate and signed an informed consent form.

\section{Results}

Twenty postmenopausal women were studied, including Group I, without hot flushes $(n=10)$ and Group II, with hot flushes $(n=10)$; both groups were without hormone therapy.

When comparing both groups there were no differences among them in age, weight, BMI, waist perimeter, hip perimeter, and WHR; only the height was significantly smaller in Group I (1.54 m [1.44-1.66] vs. $1.58 \mathrm{~m}$ [1.51-1.66], $p<0.035$ ) (Table I). In the analogue visual scale, the median of the magnitude of the hot flush was 8 (5-10).

No differences were found between the groups in $A D, P I$, and $\mathrm{RI}$ at baseline or at five minutes. When comparing among the groups the percentages of change in $A D, P I$ and RI no significant differences were found.

When comparing each group separately, in Group I at baseline the $A D$ after the hyperaemic stimulus was greater than pre stimulus, and similar results were seen for the five-minute measurement. In Group II at baseline the PI was significantly greater after the hyperaemic stimulus than before it. At one- and five-minute measurements, the $A D$ after the hyperaemic stimulus was significantly greater than before the hyperaemic stimulus (Table II).

In Group II, at the first minute measurement the post hyperaemic stimulus PI was significantly smaller when compared with the baseline post-hyperaemic stimulus $\mathrm{PI}$. The post-hyperaemic stimulus RI at five minutes was significantly smaller when compared with the baseline post-hyperaemic stimulus RI (Table II).

\section{Discussion}

In this study, no difference was found among those with and without hot flushes, which implies that the hot flush does not have an influence on vascular reac- 
Tab. II. Doppler parameters between groups without and with hot flushes

\begin{tabular}{|c|c|c|c|c|}
\hline & & & $\begin{array}{l}\text { Without hot } \\
\text { flushes }\end{array}$ & With hot flushes \\
\hline \multirow[t]{6}{*}{ Baseline } & Pre & $A D$ & $2.7(1.6-3.3)^{a}$ & $3.0(2.2-4.2)$ \\
\hline & & $\mathrm{PI}$ & $2.52(2.10-3.36)$ & $2.58(1.75-3.85)^{b}$ \\
\hline & & $\mathrm{RI}$ & $0.82(0.76-0.92)$ & $0.85(0.71-0.091)$ \\
\hline & Post & $A D$ & $3.3(2.2-4.1)^{\mathrm{a}}$ & $3.4(2.3-4.6)$ \\
\hline & & $\overline{P I}$ & $2.35(1.62-3.37)$ & $2.83(1.73-3.53)^{\mathrm{b}, t}$ \\
\hline & & $\mathrm{RI}$ & $0.82(0.74-0.87)$ & $0.85(0.75-0.91)^{\mathrm{g}}$ \\
\hline \multirow[t]{6}{*}{1 minute } & Pre & $A D$ & & $3.1(2.8-3.3)^{c}$ \\
\hline & & $\overline{P I}$ & & $2.22(1.12-3.56)$ \\
\hline & & $\mathrm{RI}$ & & $0.83(0.71-0.96)$ \\
\hline & Post & $A D$ & & $3.5(3.2-4.2)^{c}$ \\
\hline & & $\mathrm{PI}$ & & $2.35(0.92-2.97)^{f}$ \\
\hline & & $\mathrm{RI}$ & & $0.81(0.69-0.94)$ \\
\hline \multirow[t]{6}{*}{5 minutes } & Pre & $A D$ & $2.5(1.8-3.6)^{d}$ & $3.2(3.0-3.7)^{\mathrm{e}}$ \\
\hline & & $\mathrm{PI}$ & $2.45(2.12-3.35)$ & $2.50(1.38-3.18)$ \\
\hline & & $\overline{R I}$ & $0.81(0.75-0.88)$ & $0.81(0.73-0.89)$ \\
\hline & Post & $A D$ & $3.3(2.1-3.8)^{d}$ & $3.6(3.2-4.6)^{\mathrm{e}}$ \\
\hline & & $\overline{P I}$ & $2.35(1.64-3.34)$ & $2.38(1.36-3.11)$ \\
\hline & & $\mathrm{RI}$ & $0.84(0.73-0.88)$ & $0.82(0.74-0.88)^{\mathrm{g}}$ \\
\hline
\end{tabular}

Results are in median and interval. Pre - pre-hyperaemic stimulus; Post - post-hyperaemic stimulus; AD - arterial diameter (mm); PI - pulsatility index; $\mathrm{Rl}$ - resistive index

${ }^{\mathrm{a}} p<0.047$; ${ }^{\mathrm{b}} p<0.022$; $^{\mathrm{c}} p<0.008$; $p<0.032$; $^{\mathrm{e}} p<0.007$; $^{\mathrm{f}} p<0.019$ ${ }^{\mathrm{g}} p<0.028$

tivity. This goes against reports by other authors, who found that the women with hot flushes had a lower flow-mediated dilation than those without hot flushes $[6,13]$, although in another study no differences were found between dependent and independent endothelial responses among those that had or did not have hot flushes [14].

It has been reported that those with hot flushes have greater aortic calcification [6]; however, in early postmenopause, hot flushes seems not to have any influence on carotid IMT [13]. Also, it has been reported that those women with hot flushes have lower levels of high-density lipoprotein cholesterol and Apo lipoprotein A1, and greater levels of ICAM-1 [14], total cholesterol, glucose, and triglycerides [15], although others have not confirmed those findings [16]. The effect of hot flushes on vascular endothelium varies depending on the study. In our study the lack of changes might be due to the "short" time since menopause in the studied population.

An interesting finding was that in those with hot flushes $\mathrm{PI}$ and $\mathrm{RI}$ (at one- and five-minute measure- ments) were smaller than PI and RI at baseline after hyperaemic stimulus, which might indicate a vasodilator effect, as has been reported [17].

The study carried out in the hospital has the inconvenience of a small sample size, which perhaps prevented detection of differences. However, the strength of this work was that it was the first to evaluate $A D, P I$, and RI near to the hot flush.

The literature continues to be inconclusive regarding the effect of hot flushes on cardiovascular health, so it is advisable to increase the sample size and to repeat this study analysing other cardiovascular risk factors.

At this time it is possible to conclude that no difference was found when comparing those without and with hot flushes.

\section{Disclosure}

Authors report no conflict of interest.

\section{References}

1. National Institutes of Health. National Institutes of Health State-of-theScience Conference statement: management of menopause related symptoms. Ann Intern Med 2005; 142 (12 Pt 1): 1003-1013.

2. Woods NF, Mitchell ES. Symptoms during the perimenopause: prevalence, severity, trajectory, and significance in women's lives. Am J Med 2005; 118 Suppl 12B: 14-24.

3. Gold EB, Colvin A, Avis N, et al. Longitudinal analysis of the association between vasomotor symptoms and race/ethnicity across the menopausal transition: study of women's health across the nation. Am J Public Health 2006; 96: 1226-1235.

4. Randolph JF, Sowers M, Bondarenko I, et al. The relationship of longitudinal change in reproductive hormones and vasomotor symptoms during the menopausal transition. J Clin Endocrinol Metab 2005; 90: 6106-6112.

5. McKinlay SM. The normal menopause transition: an overview. Maturitas 1996; 23: 13-45.

6. Thurston RC, Sutton-Tyrrell K, Everson-Rose SA, et al. Hot flashes and subclinical cardiovascular disease: findings from the Study of Women's Health Across the Nation Heart Study. Circulation 2008; 118: 1234-1240.

7. Crandall CJ, Tseng CH, Crawford SL, et al. Association of menopausal vasomotor symptoms with increased bone turnover during the menopausal transition. J Bone Miner Res 2011; 26: 840-849.

8. Barnabei VM, Cochrane BB, Aragaki AK, et al. Menopausal symptoms and treatment-related effects of estrogen and progestin in the Women's Health Initiative. Obstet Gynecol 2005; 105: 1063-1073.

9. Finck G, Barton DL, Loprinzi CL, et al. Definitions of hot flashes in breast cancer survivors. J Pain Symptom Manage 1998; 16: 327-333.

10. Carranza-Lira S, Reyes Razo BP, Chan Verdugo R. SUMEVA, a new system of climacteric symptom evaluation, and its correlation with FSH and estradiol levels. Int J Fertil Womens Med 2006; 51: 140-144.

11. Cai H, Harrison DG. Endothelial dysfunction in cardiovascular diseases: the role of oxidant stress. Circ Res 2000; 87: 840-844.

12. Yeboah J, Crouse JR, Hsu FC, et al. Brachial flow-mediated dilation predicts incident cardiovascular events in older adults. The Cardiovascular Health Study. Circulation 2007; 115: 2390-2397.

13. Bechlioulis A, Kalantaridou SN, Naka KK, et al. Endothelial function, but not carotid intima-media thickness, is affected early in menopause and is associated with the severity of hot flushes. J Clin Endocrinol Metab 2010; 95: 1199-1206.

14. Sassarini J, Fox H, Ferrell W, et al. Vascular function and cardiovascular risk factors in women with severe flushing. Clin Endocrinol (Oxf) 2011; 74: 97-103. 
15. Gast GC, Samsioe GN, Grobbee DE, et al. Vasomotor symptoms, estradiol levels and cardiovascular risk profile in women. Maturitas 2010; 66: 285-290.

16. Tuomikoski P, Mikkola TS, Hämäläinen $E$, et al. Biochemical markers for cardiovascular disease in recently postmenopausal women with or without hot flashes. Menopause 2010; 17: 145-151.

17. Tuomikoski P, Ylikorkala O, Mikkola TS. Menopausal hot flushes and vascular health. Ann Med 2011; 43: 283-291. 